\title{
The Persian, Last 7-day, Long form of the International Physical Activity Questionnaire: Translation and Validation Study
}

\author{
Ali Vasheghani-Farahani ${ }^{1,2 *}$, MD; Maryam Tahmasbi ${ }^{2}$, MD; Hossein Asheri ${ }^{1}$, MD, MPH; Haleh Ashraf ${ }^{2}$, MD; \\ Saharnaz Nedjat ${ }^{3}$, MD, MPH; Ramin Kordi ${ }^{1}$, MD, PhD
}

Authors' Affiliation:

1. Sports Medicine Research Centre, Tehran University of Medical Sciences, Tehran, Iran

2. Department of Cardiology, Tehran Heart Center, Tehran University of Medical Sciences, Tehran, Iran

3. School of Public Health, Tehran University of Medical Sciences, Tehran, Iran

* Corresponding Author; Address: Department of Cardiology, Tehran Heart Center, North Kargar Ave., Tehran, Iran

E-mail: avasheghani@sina.tums.ac.ir

Received: Apr 11, 2011

Accepted: May 13, 2011

Key Words: Metabolic equivalent; Physical Activity; Questionnaire; Reliability and Validity; IPAQ

\section{Abstract}

Purpose: To translate long form, interview-administered International Physical Activity Questionnaire (IPAQ) from English to Persian and evaluate its validity, reliability and reproducibility.

Methods: A forward-backward translation procedure was followed to develop the Persian version of the IPAQ. A total of 218 respondents (53.7\% women, aged 22-76 yr) completed the Persian version in Tehran, Iran. To examine the test-retest reliability, 48 healthy volunteers completed the IPAQ twice during a 7-day period. . The PA indicators derived from the IPAQ were assessed for reliability and were compared with aerobic fitness and body mass index (BMI) for construct validity.

Results: In general, the questionnaire was received well and all domains met the minimum reliability standards (intra-class correlation [ICC]> 0.7), except for Leisure-time physical activity (PA). Aerobic fitness showed a weak positive correlation with all of the PA results derived from the IPAQ. A significant correlation was observed between the IPAQ data for total PA and both aerobic fitness $(r=0.33$, $P<0.001)$ and BMI $(r=0.26, P<0.001)$. Performing a known group comparison analysis, the results indicated that the questionnaire was discriminated well between the subgroups of the study samples expected to be different in their physical activity.

Conclusions: The Persian version of the long form, interviewadministered IPAQ had an acceptable reliability and validity for assessing total PA in our Iranian sample of individuals. It may be a useful instrument for generating internationally comparable data on PA.

Asian Journal of Sports Medicine, Volume 2 (Number 2), June 2011, Pages: 106-116

\section{INTRODUCTION}

$\mathrm{D}$ espite the general agreement regarding the significant effects of physical activity (PA) on well-being, health, cardiovascular morbidity and mortality, and longevity ${ }^{[1]}$, there is still a need for more precise methods to assess the amount and the pattern of health-related PA that can take place in 
different settings.

In epidemiologic studies, questionnaires are the most commonly used instruments to measure PA, owing to their low cost, simplicity and briefness ${ }^{[2]}$. In 1997, a group of public health and PA researchers from 16 countries, with support of the World Health Organization (WHO) and the US Centers for Disease Control and Prevention (CDC), gathered in Geneva, Switzerland, to identify a common method to assess PA for the purpose of population surveillance ${ }^{[3]}$. The outcome of the meeting was the development of the International Physical Activity Questionnaire (IPAQ), as an instrument for cross-national monitoring of PA. Reliability and validity evaluation of the IPAQ is important as it can indicate which aspects of PA are being measured, how well they are measured and thereby how they can aid interpreting and facilitating comparisons across different studies. The IPAQ has then been examined for validity and reliability in several populations and international studies are deemed acceptable to use the IPAQ in PA research and surveillance activities ${ }^{[3-8]}$. Although the results of former studies are promising, there is no available Persian-language version that is culturally adapted and validated for Iranian habits and lifestyle.

There are two versions of the IPAQ (long and short forms). In each version, there are two formats: selfadministered and telephone or face-to-face interview [9]. Most countries where IPAQ has been studied expressed a qualitative preference for using the short form as it seems to be more acceptable to both investigators and survey respondents. However, interest has now been raised towards the long form of the IPAQ and its suitability for being used in research and population prevalence studies ${ }^{[3,6]}$.

The purpose of the present study was to translate the interview-administered, last 7-day, long form of the IPAQ into Persian and to examine the psychometric properties of the questionnaire in a sample of participants attended an exercise tolerance test clinic (healthy volunteers and those with a moderate pretest probability). We assessed the validity of the IPAQ indirectly by comparing its results with maximal oxygen uptake $\left(\mathrm{VO}_{2 \max }\right)$, as a measure of cardiorespiratory fitness, and body mass index (BMI) ${ }^{[7]}$.

\section{METHODS AND SUBJECTS}

\section{Study participants and data collection:}

The long form of the IPAQ was administered to a sample of 218 individuals aged 18 and above (with no upper age limitation). To avoid the selection bias regarding illiterate participants and also to reduce the number of missing responses, we decided to use interview instead of a self-completion mode for data collection. In this sample, there were 48 healthy volunteers who stated to be free of a chronic medical condition and not receiving any therapeutic interventions. The participants attended an exercise tolerance test (ETT) clinic with a moderate pretest probability (having nonspecific symptoms but positive cardiovascular risk factors or having a typical chest pain without risk factors). All participants were individually interviewed by a trained interviewer. These data were used for internal consistency and known group comparison analyses. To assess reproducibility, every respondent in the healthy sample $(\mathrm{n}=48)$ was asked to complete the questionnaire once more one week later, using a test-retest design with the same instructions. The ethics committee of Tehran University of Medical Sciences approved the research and all participants gave informed consents.

Weight $(\mathrm{kg})$ was measured while the patient was dressed in light clothing without shoes using digital scales and recorded to the nearest $0.5 \mathrm{Kg}$. Height was measured and recorded to the nearest $0.5 \mathrm{~cm}$ in a standing position, without shoes, using a wall-mounted tape measure, while the shoulders were in a normal position. BMI was calculated as weight (in kilograms) divided by height (in meters) squared.

\section{The questionnaire:}

The IPAQ is used to assess habitual PA during the past 7 days. There are two versions, the long form (27 items) and the short form ( 7 items), which can be selfadministered or administered during in-person or telephone interviews. The IPAQ used in the present study is the long interview-administered version which covers four domains of PA: occupational (7 items), transportation (6 items), household/gardening (6 items) and leisure-time activities (6 items). The questionnaire also includes two questions about the time spent on 
sitting as an indicator of sedentary behavior. The number of days per week and the time spent on walking per day as well as moderate and vigorous activities from all four domains are recorded. Practical examples of culturally relevant activities of moderate and vigorous intensity are given. The IPAQ data were converted to metabolic equivalent scores (MET-minweek $^{-1}$ ) for each type of activity, by multiplying the number of minutes dedicated to each activity class by the specific MET score for that activity. The MET score weighs each type of activity by its energy expenditure. One MET is equal to energy expenditure during rest and is approximately equal to $3.5 \mathrm{ml} \mathrm{O}_{2} / \mathrm{kg} /$ min in adults. Physical activity levels were also classified into three categories: inactive, minimally active and health-enhancing physically active, according to the scoring system provided by the IPAQ. Furthermore, sufficient vigorous activity was computed on the basis of 3 or more days of vigorous-intensity activity of at least 20 minutes per day. Likewise, sufficiently moderate and walking activities were computed based on 5 or more days of moderateintensity and walking of at least 30 minutes per day ${ }^{[9]}$.

\section{Translation:}

The standard "forward-backward" procedure was applied to translate the questionnaire from English into Persian using the instructions given in the IPAQ manual for reliability and validity ${ }^{[9]}$.

Two independent bilinguals translated the items into Persian, and subsequently the preliminary version was back translated into English following careful cultural adaptation. Then a third bilingual translator provided a final version (Appendix). The aim of the cultural adaptation was to produce a version that was conceptually as close as possible to the original questionnaire, considering the patients' understanding.

\section{Maximal oxygen uptake (VO2max):}

We used $\mathrm{VO}_{2 \max }$ which reflects cardiorespiratory fitness ${ }^{[9,10]}$, as an indicator of PA. A correlation between VO2max and PA assessed using the questionnaire would suggest that the questionnaire could measure some aspects of PA, such as aerobic training, that may lead to improved fitness.
Each patient performed an incremental, symptomlimited ETT to the maximal tolerable level on a treadmill, using the standard Bruce Protocol. The subjects were instructed not to eat or smoke for at least 2 hours before the test. Water could be taken at any time, as needed. No unusual physical activity efforts should have been performed at least 12 hours before testing, and the subjects had to dress appropriately for exercise, especially with regard to footwear. Before the $\mathrm{VO}_{2 \max }$ test, the participants also signed a statement that they were healthy and fit for the $\mathrm{VO}_{2 \max }$ test on treadmill.

The test began at a speed of $4.8 \mathrm{~km} / \mathrm{hour}$ at zero gradient. The gradient was raised by $3 \%$ every three minutes up to $15 \%$. The heart rate was measured throughout the test, using a Polar Vantage NV monitor (Polar Electro OY, Kempele, Finland). During the last minute of each stage, perceived exhaustion was assessed using the Borg RPE 6-20 scale. The maximal aerobic power was calculated from the last heart rate at the final stage using a modified Balke formula ${ }^{[10]}$.

\section{Statistical analysis:}

All data analyses were performed using the Statistical Package for the Social Science (SPSS for Windows Ver. 16.0, SPSS Inc., Chicago, IL). The descriptive characteristics were reported as means \pm standard deviations or percentages. The median and the range were also presented for the physical activity data because of their skewed distributions. The MannWithney test was used to compare the differences in continuous variables, and the chi-square test was used for categorical variables. The psychometric properties of the IPAQ were assessed using different statistical tests as follows.

\section{Test-retest reliability:}

To evaluate the reliability of the IPAQ, Spearman's correlation coefficients were calculated for the testretest comparisons. The reliability was assessed in healthy individuals by an intraclass correlation coefficient (ICC, one-way random-effects model). The ICC is an estimate of the fraction of the total measurement variability due to variations among individuals ${ }^{[12]}$. We expected that the ICC for each IPAQ domain and the overall score will exceed 0.7. 


\section{Construct validity:}

To assess the validity, Spearman correlation coefficients were used to measure the association of the IPAQ responses with $\mathrm{VO}_{2 \max }$ or BMI.

\section{Known groups comparisons:}

The ability of the IPAQ to discriminate between active and inactive groups expected was tested by performing the Mann-Withney test. We expected that the symptomatic subjects, those who are obese (BMI $\geq 30$ ) or have a positive ETT, will have significantly lower scores compared to the healthy volunteers or the patients without these two conditions.

\section{RESULTS}

In all, 218 individuals (ages $22-76 \mathrm{yr}, 53.7 \%$ women) were interviewed and 48 of them were healthy volunteers. The characteristics of the respondents are shown in Table 1. There was no significant difference between the mean age of males ( $44.2 \pm 12.0$ years $)$ and females (46.5 \pm 8.5 years). About two-third of the males and one-third of the females had a job.

\section{Descriptive statistics:}

Table 2 shows the data from different domains and intensities of the IPAQ. On the basis of energy expenditure estimated by the IPAQ, PA at work was the most common form of activity, which contributed to more than $50 \%$ of the total MET counts. Women reported a more moderate intensity PA than men [3262.7 $( \pm 4354.5)$ vs. $2246 \quad( \pm 4599.4) \quad$ (MET-min week $\left.\left.^{-1}\right) ; P<0.001\right]$, while men were mostly involved in walking $\left[\begin{array}{lll}1754.7 & ( \pm 2329.4) & \text { vs. } 887.6 \quad( \pm 912.4)\end{array}\right.$ $\left(\mathrm{MET}-\mathrm{min}\right.$ week $\left.\left.^{-1}\right) ; P=0.03\right]$ and vigorous PA [1348.5 $( \pm 4843.5)$ vs. $600 \quad( \pm 1857.6) \quad\left(\right.$ MET-min week $\left.^{-1}\right)$; $P=0.06]$.

Table 3 summarizes the PA profile of the study subjects, based on three activity categories. More than $30 \%$ of the subjects were inactive, whereas about $57 \%$ were minimally active and $12 \%$ were active. Inactivity was higher in males. Females were engaged in healthenhancing physical activities more than males. The proportion of the study subjects who were sufficiently and vigorously active, based on 3 or more days of vigorous-intensity activity of at least $20 \mathrm{~min}$ per day, was $19.3 \%$ (21.8\% for males and $17.1 \%$ for females). Furthermore, $65.0 \%$ (47.5\% for males and $80.2 \%$ for females) of the individuals reported sufficient moderate and walking activities, based on 5 or more days of moderate-intensity activity and walking of at least 30 min per day.

\section{Reliability tests:}

A total of 48 subjects participated in the test-retest analysis. The subjects completed the second set of questionnaires 7 days after completing the first set of the questionnaires. Table 4 shows the results of the test-retest reliability analysis using the average measure ICC and 95\% confidence interval for each scale in the questionnaire. With the exception of Leisure-time PA, The ICC for the overall score and other IPAQ domains showed acceptable correlation coefficients $(a>0.7)^{[12]}$. Spearman's correlation

Table 1: Characteristics of the study participants in IPAQ-C validation study

\begin{tabular}{lccc} 
Parameter & Women & Men & P value \\
\hline Age (yr) & $\mathbf{N = 1 1 7}$ & $\mathbf{N = 1 0 1}$ & 0.09 \\
Height (cm) & $46.5(8.5)$ & $44.2(12.0)$ & $<0.001$ \\
Weight (kg) & $156.7(12.0)$ & $172.8(8.2)$ & $<0.001$ \\
Body Mass Index (kg.m-2) & $70.6(17.9)$ & $80.9(13.1)$ & $<0.001$ \\
Aerobic fitness (ml O2 kg-1 min-1) & $30.1(23.3)$ & $27.1(3.9)$ & $<0.001$
\end{tabular}

Values are expressed as mean (standard deviation) / IPAQ-C: International Physical Activity Questionnaire-Persian version 
Table 2: Descriptive data from different domains and intensities of the IPAQ-C

\begin{tabular}{|c|c|c|c|c|c|c|c|}
\hline & \multicolumn{2}{|c|}{ Total } & \multicolumn{2}{|c|}{ Women } & \multicolumn{2}{|c|}{ Men } & \multirow{2}{*}{$\begin{array}{c}\boldsymbol{P} \\
\text { Value* }\end{array}$} \\
\hline & $\begin{array}{l}\text { Mean } \\
\text { (SD) }\end{array}$ & $\begin{array}{l}\text { Median } \\
\text { (range) }\end{array}$ & $\begin{array}{l}\text { Mean } \\
\text { (SD) }\end{array}$ & $\begin{array}{l}\text { Median } \\
\text { (range) }\end{array}$ & $\begin{array}{l}\text { Mean } \\
\text { (SD) }\end{array}$ & $\begin{array}{l}\text { Median } \\
\text { (range) }\end{array}$ & \\
\hline $\begin{array}{l}\text { Total PA excluding } \\
\text { sitting }\end{array}$ & $\begin{array}{c}5034 \\
(7491)\end{array}$ & $\begin{array}{c}2719.5 \\
(0-78342)\end{array}$ & $\begin{array}{c}4759.4 \\
(5584.7)\end{array}$ & $\begin{array}{c}3026.2 \\
(0-36453)\end{array}$ & $\begin{array}{c}5349.3 \\
(9227.4)\end{array}$ & $\begin{array}{c}2535 \\
(0-78342)\end{array}$ & 0.4 \\
\hline $\begin{array}{l}\text { Domains (MET-min } \\
\text { week }^{-1} \text { ) }\end{array}$ & $\begin{array}{c}2683.3 \\
(6382.9)\end{array}$ & $\begin{array}{c}243.7 \\
(0-72744)\end{array}$ & $\begin{array}{c}1944 \\
(3545.7)\end{array}$ & $\begin{array}{c}0 \\
(0-17748)\end{array}$ & $\begin{array}{c}3539.8 \\
(8511.5)\end{array}$ & $\begin{array}{c}693 \\
(0-72744)\end{array}$ & 0.004 \\
\hline PA at work & $\begin{array}{c}514.3 \\
(856.1)\end{array}$ & $\begin{array}{c}231 \\
(0-6426)\end{array}$ & $\begin{array}{c}469.8 \\
(781.0)\end{array}$ & $\begin{array}{c}264 \\
(0-6426)\end{array}$ & $\begin{array}{c}565.9 \\
(936.9)\end{array}$ & $\begin{array}{c}198 \\
(0-5292)\end{array}$ & 0.4 \\
\hline $\begin{array}{l}\text { PA during } \\
\text { transport }\end{array}$ & $\begin{array}{c}1203.3 \\
(2089.2)\end{array}$ & $\begin{array}{c}360 \\
(0-14520)\end{array}$ & $\begin{array}{c}1818.4 \\
(2542.2)\end{array}$ & $\begin{array}{c}940 \\
(0-14520)\end{array}$ & $\begin{array}{c}496.9 \\
(1025.8)\end{array}$ & $\begin{array}{c}0 \\
(0-5985)\end{array}$ & $\begin{array}{c}<0.00 \\
1\end{array}$ \\
\hline $\begin{array}{l}\text { PA at home or in } \\
\text { garden }\end{array}$ & $\begin{array}{c}1325.3 \\
(1772.9)\end{array}$ & $\begin{array}{c}759 \\
(0-13068)\end{array}$ & $\begin{array}{l}954.6 \\
(50.4)\end{array}$ & $\begin{array}{c}693 \\
(0-4653)\end{array}$ & $\begin{array}{c}1754.7 \\
(2329.4)\end{array}$ & $\begin{array}{c}957 \\
(0-13068)\end{array}$ & 0.08 \\
\hline Leisure-time PA & $\begin{array}{c}2028.2 \\
(1252.2)\end{array}$ & $\begin{array}{c}1920 \\
(0-13068)\end{array}$ & $\begin{array}{c}1868.0 \\
(1177.7)\end{array}$ & $\begin{array}{c}1680 \\
(0-67200)\end{array}$ & $\begin{array}{c}2213.8 \\
(1314.8)\end{array}$ & $\begin{array}{c}2220 \\
(0-6720)\end{array}$ & 0.02 \\
\hline $\begin{array}{l}\text { Time spent sitting } \\
\left(\text { min week }^{-1}\right)\end{array}$ & $\begin{array}{c}2499.2 \\
(1547.2)\end{array}$ & $\begin{array}{c}2295 \\
(0-11640)\end{array}$ & $\begin{array}{c}219.5 \\
(1286.9)\end{array}$ & $\begin{array}{c}2100 \\
(0-7140)\end{array}$ & $\begin{array}{c}2855.5 \\
(1741.8)\end{array}$ & $\begin{array}{c}2550 \\
(160-11640)\end{array}$ & 0.002 \\
\hline \multicolumn{8}{|l|}{ Intensities } \\
\hline Vigorous PA & $\begin{array}{c}946.8 \\
(3577)\end{array}$ & $\begin{array}{c}0 \\
(0-40800)\end{array}$ & $\begin{array}{c}600.0 \\
(1857.6)\end{array}$ & $\begin{array}{c}0 \\
(0-14400)\end{array}$ & $\begin{array}{c}1348.5 \\
(4843.5)\end{array}$ & $\begin{array}{c}0 \\
(0-40800)\end{array}$ & 0.06 \\
\hline Moderate & $\begin{array}{c}2789.5 \\
(4488.6)\end{array}$ & $\begin{array}{c}1080 \\
(0-29880)\end{array}$ & $\begin{array}{c}3262.7 \\
(4354.5)\end{array}$ & $\begin{array}{c}1755 \\
(0-29880)\end{array}$ & $\begin{array}{c}2246 \\
(4599.4)\end{array}$ & $\begin{array}{c}410 \\
(0-27840)\end{array}$ & $\begin{array}{c}<0.00 \\
1\end{array}$ \\
\hline Walking & $\begin{array}{c}1289.3 \\
(1770.1)\end{array}$ & $\begin{array}{c}701.2 \\
(0-13068)\end{array}$ & $\begin{array}{l}887.6 \\
(12.4)\end{array}$ & $\begin{array}{c}627 \\
(0-4653)\end{array}$ & $\begin{array}{c}1754.7 \\
(2329.4)\end{array}$ & $\begin{array}{c}957 \\
(0-13068)\end{array}$ & 0.03 \\
\hline
\end{tabular}

* P values for comparison between females and males. Student's t-test for mean comparisons.

IPAQ-C: International Physical Activity Questionnaire-Persian version / PA: Physical Activity / SD: standard deviation

coefficients for the test- retest comparison were 0.624 $(P<0.001)$ for PA at work, $0.491(P<0.001)$ PA during transport, $0.828(P<0.001) \mathrm{PA}$ at home or in garden and $0.306(P=0.03)$ for Leisure-time PA.

\section{Construct validity:}

Aerobic fitness showed a weak positive correlation with all of the PA variables derived from the IPAQ (Table 5). There was a weak negative correlation

Table 3: Physical activity profile of the study subjects (\%)

\begin{tabular}{lccc} 
Activity category & All & Males & Females \\
\hline Inactive* $^{*}$ & 30.7 & 44.6 & 18.8 \\
Minimally active $^{\dagger}$ & 43.6 & 23.8 & 60.7 \\
Active $^{\ddagger}$ & 25.7 & 31.7 & 20.5
\end{tabular}

$\chi^{2}=31.3$; two-sided level of significance $<0.001$.

$*$ Not meeting criteria for minimally active or active.

$\dagger$ Meeting any of the following conditions: 1) participating in 3 or more days of vigorousintensity activity for at least $20 \mathrm{~min}$ per day, or 2) participating in 5 or more days of moderateintensity activity or walking for at least $30 \mathrm{~min}$ per day, or 3 ) participating in 5 or more days of any combination of walking, moderate-intensity or vigorous-intensity activities achieving a minimum of at least 600 MET-min per week (MET = metabolic equivalent).

$\ddagger$ Meeting either of the following criteria: 1 ) vigorous-intensity activity on at least 3 days achieving at least 1500 MET-min per week, or 2) taking part in 7 or more days of any combination of walking, moderate-intensity or vigorous-intensity activities achieving a minimum of at least 3000 MET-min per week. 
Table 4: Test -retest reliability of the IPAQ-C (MET-min week ${ }^{-1}$ )

\begin{tabular}{|c|c|c|c|c|}
\hline \multicolumn{2}{|c|}{ IPAQ (MET-min week ${ }^{-1}$ ) } & $\begin{array}{c}\text { Reliability of } \\
\text { Scale (Unbiased) }\end{array}$ & $\begin{array}{c}\text { ICC (95\% CI) } \\
\text { (average measure) }\end{array}$ & P value \\
\hline \multicolumn{2}{|c|}{ Total PA excluding sitting } & 0.842 & $0.835(.706-.908)$ & $<0.001$ \\
\hline \multirow[t]{5}{*}{ Domains } & PA at work & 0.803 & $0.794(0.632-0.884)$ & $<0.001$ \\
\hline & PA during transport & 0.699 & $0.686(0.440-0.824)$ & $<0.001$ \\
\hline & PA at home or in garden & 0.888 & $0.883(0.791-0.934)$ & $<0.001$ \\
\hline & Leisure-time PA & 0.534 & $0.514(0.264-0.699)$ & $<0.001$ \\
\hline & Time spent sitting (min week ${ }^{-1}$ ) & 0.742 & $0.731(0.520-0.849)$ & $<0.001$ \\
\hline \multirow[t]{3}{*}{ Intensities } & Vigorous PA & 0.865 & $0.859(0.748-0.921)$ & $<0.001$ \\
\hline & Moderate & 0.830 & $0.823(0.684-0.901)$ & $<0.001$ \\
\hline & Walking & 0.736 & $0.724(0.507-0.845)$ & $<0.001$ \\
\hline
\end{tabular}

ICC: Intraclass coefficient / PA: physical activity

between BMI as well as total PA $(r=-0.256, P<0.001)$ and moderate PA $(r=-0.230, P=0.001)$. There was no significant relationship between $\mathrm{BMI}$ and vigorous activity derived from the IPAQ $(P=0.07)$.

\section{Known group comparisons:}

As we supposed, the symptomatic subjects who were obese $(\mathrm{BMI} \geq 30$ ) or had a positive exercise test were less active compared to the healthy volunteers or patients not having these two conditions. As shown in Table 6, scores in all domains were significantly different in these groups. The two groups (61 symptomatic vs. 157 healthy participants) were comparable regarding age $(47.3( \pm 9.1)$ vs. $44.7( \pm 10.7)$;
$P=0.1$ ) and sex distribution (\% of women: $52.5 \%$ vs. $54.1 \%, P=0.9)$.

Table 5: Spearman rank correlation coefficients (r) for reported time of physical activity in different domains from the International Physical Activity Questionnaire (IPAQ) and measures of construct validity $(n=46)$

\begin{tabular}{|c|c|c|c|}
\hline Construct measure & IPAQ measure (MET-min week ${ }^{-1}$ ) & $\mathbf{R}$ & $P$ value \\
\hline \multirow{4}{*}{$\begin{array}{l}\text { Aerobic fitness }\left(\mathrm{ml} \mathrm{O}_{2} \mathrm{~kg}^{-1}\right. \\
\left.\mathrm{min}^{-1}\right)\end{array}$} & walking PA & 0.282 & $<0.001$ \\
\hline & Moderate PA & 0.225 & $<0.001$ \\
\hline & Vigorous PA & 0.287 & 0.03 \\
\hline & Total PA & 0.332 & $<0.001$ \\
\hline \multirow{4}{*}{ BMI $\left(\mathbf{k g} / \mathbf{m}^{2}\right)$} & walking PA & -0.195 & 0.004 \\
\hline & Moderate PA & -0.230 & 0.001 \\
\hline & Vigorous PA & -0.123 & 0.07 \\
\hline & Total PA & -0.256 & $<0.001$ \\
\hline
\end{tabular}

BMI: body mass index / PA: physical activity 
Table 6: IPAQ comparisons between obese or positive exercise test groups and healthy volunteers

\begin{tabular}{|c|c|c|c|c|}
\hline \multicolumn{2}{|c|}{ IPAQ (MET-min week ${ }^{-1}$ ) } & healthy volunteer & Symptomatic patients & $P$ value \\
\hline \multicolumn{2}{|c|}{ Total PA excluding sitting } & $6007.8 \pm 8441.8$ & $2543.5 \pm 3021.1$ & $<0.001$ \\
\hline \multirow[t]{5}{*}{ Domains } & PA at work & $3496.8 \pm 7318.7$ & $681.9 \pm 1956.2$ & $<0.001$ \\
\hline & PA during transport & $568.8 \pm 960.1$ & $380.4 \pm 499.7$ & 0.06 \\
\hline & PA at home or in garden & $1307.3 \pm 2134.9$ & $949.2 \pm 1966.2$ & 0.2 \\
\hline & Leisure-time PA & $1512.1 \pm 1965.4$ & $865.6 \pm 1051.2$ & 0.002 \\
\hline & Time spent sitting (min week $\left.{ }^{-1}\right)$ & $1941.9 \pm 1257.4$ & $2240.6 \pm 1223.2$ & 0.1 \\
\hline \multirow[t]{3}{*}{ Intensities } & Vigorous PA & $1212.4 \pm 4185.9$ & $293.3 \pm 806.2$ & 0.01 \\
\hline & Moderate & $3382.2 \pm 4975.6$ & $1340.7 \pm 2468.1$ & $<0.001$ \\
\hline & Walking & $1466.7 \pm 1967.8$ & $853.02 \pm 1037.4$ & 0.003 \\
\hline
\end{tabular}

PA: physical activity

IPAQ: International Physical Activity Questionnaire

international standardized questionnaire in a sample of Iranian adults.

Validation and reliability of this questionnaire were performed previously through the collaboration of 14 participant centers from 12 different countries. The results from the 12-country reliability test produced repeatable data for all questionnaire versions tested (Spearman's $r$ of 0.81 for the long form and 0.76 for the short form) with correlated but not directly comparable data from the short and the long version 7 and they demonstrated that IPAQ instruments have acceptable measurement properties for monitoring population levels of physical activity among 18- to 65year-old adults in diverse settings. The reliability of our long version of the IPAQ was comparable with the original reliability studies of this questionnaire ${ }^{[3]}$. We found that the IPAQ showed a satisfactory reproducibility; there was a significant correlation between reported activity measures using the IPAQ on day 1 compared to day 8 , indicating a minimal reactivity during the 7 days of consecutive measurement and the intra-class correlation coefficient in most (all except Leisure-time PA) domains was more than $0.70^{[12]}$. Here, the repeatability for the question concerning leisure time PA was poor, even in one week, indicating that these activities were difficult to recall or that light activity must be operationalized or better defined in the questionnaire to make recall easier.
Regarding the known group comparisons, there were significant differences between the subgroups of the study samples expected differing to be different in their PA, indicating that the questionnaire has an acceptable discriminative validity.

For self-reported PA, a key concern is how well and accurate reported PA represents habitual activity. In the absence of a "gold standard", $\mathrm{VO}_{2 \max }$ which represents cardiorespiratory fitness has been used as a validation standard for PA surveys ${ }^{[14]}$. However, a perfect correlation between self-reported PA and cardiorespiratory fitness would not be expected due to for example genetic factors. Singh et al. suggested that strong correlations of PA with aerobic fitness may perhaps be observed only for vigorous sweat producing activities ${ }^{[15]}$. Consistent with these patterns, some authors have found that correlations with fitness have been the largest for the hardest form of activity and concluded that the ability to assess habitual PA was greater for vigorous than lower intensity PA ${ }^{[16-19]}$. On the other hand, in the study of Hagströmer et al ${ }^{[6]} \mathrm{a}$ relatively weak, although significant, correlation between both total and moderate PA derived from the IPAQ and aerobic fitness was found. This is while the relationship between vigorous-intensity PA derived from the IPAQ and aerobic fitness was not significant. A similar correlation was reported by Wareham et al [20] when comparing the time spent on vigorousintensity PA with aerobic fitness using another self- 
report instrument. Our results also suggest that aerobic fitness has a weak positive correlation with all of the PA variables derived from the IPAQ. Fitness, and in particular the when measured by VO2max, only reflects one aspect of PA. PA has many dimensions in addition to those that lead to improved fitness. For example, motion sensor scores may show weak relationships with $\mathrm{VO}_{2 \max }{ }^{[21]}$.

There was a weak negative correlation between BMI and responses in our study to the moderate question, but they had no significant relationship with vigorous activity derived from the IPAQ. No significant correlation was found between any of the PA variables from the IPAQ and Body Fat (\%) in the study of Hagströmer and colleagues ${ }^{[6]}$.

Some investigators have noted high prevalence estimates from the IPAQ high PA category ${ }^{[22]}$. In the current study, about one fifth of the subjects were sufficiently and vigorously active and nearly two thirds were sufficiently and moderately active. Rzewnicki et al ${ }^{[23]}$ studied this concern in 50 Belgian adults and observed that $40 \%$ of the subjects overreported vigorous- and moderate-intensity PA, and more than two thirds overreported "walking" on the IPAQ. They concluded that only trained interviewers were familiar with the overreporting issues and computer-assisted telephone interview systems programmed to detect overreporting should be used to administer the IPAQ to avoid this problem. Although we only used trained interviewers to restrict abnormally high values and minimize the overreporting of PA data, we cannot rule out the possibility of this occurrence.

The finding in the present report that females were more moderately active than males deserves some comment. The IPAQ instrument assessed all components of PA including moderate-intensity activities done at home, such as carrying loads (e.g. babies), scrubbing floors, sweeping and vacuuming. These types of physical activity are more likely to be performed by Iranian females, especially when considering the fact that more than two third of the females in our sample were not working. Indeed, men usually report greater levels of total and vigorous physical activities, whereas women tend to report participating in low to moderate activities which is consistent with most previous studies ${ }^{[24-26]}$. The preceding discussion, however, cannot rule out the overreporting of moderate-intensity physical activity by the female respondents in the present study.

The present study is subject to the following limitations. First, as is the case with any questionnaire, the respondents could have suffered from recall bias as well as social desirability bias. Second, the data of this study may not be representative of the general population which may have inflated our estimates. Lastly, we assessed validity indirectly by comparing it with VO2max and BMI instead of the use of more direct, expensive measurements such as accelerometers.

\section{CONCLUSION}

This study has provided some preliminary evidence of the reliability and validity of the last 7-day, long form of the IPAQ for being used in Iran. In conclusion, the results of our analysis demonstrate that this interviewadministered questionnaire in a sample of Iranian adults showed such satisfactory levels of consistency and reliability that can be used for measuring physical activity in Iran.

\section{ACKNOWLEDGMENTS}

The authors would like to thank Sports Medicine Research Center and Tehran Heart Center for their support. We also appreciate Miss Mohammadi and research nurses for their grateful help. This study is supported by Tehran University of Medical Sciences Grant No. 85-02-30-3852.

Conflict of interests: None 


\section{REFERENCES}

1. Blair SN, Kampert JB, Kohl HW III, et al. Influences of cardiorespiratory fitness and other precursors on cardiovascular disease and all-cause mortality in men and women. JAMA 1996;276:205-10.

2. Ga'lvez Vargas R, Sierra Lo'pez A, Sae'nz Gonza'lez MC, et al (eds). In: Piédrola Gil. Medicina Preventiva y Salud $\mathrm{Pu}^{\prime}$ blica. 10 ed. Barcelona: Masson. 2000, Pp: 935-43.

3. Craig CL, Marshall AL, Sjostrom M, et al. International physical activity questionnaire: 12-country reliability and validity. Med Sci Sports Exerc 2003;35:1381-95.

4. Deng HB, Macfarlane DJ, Thomas GN, et al. Reliability and validity of the IPAQ-Chinese: The Guangzhou Biobank Cohort Study. Med Sci Sports Exerc 2008;40:303-7.

5. Ekelund U, Sepp H, Brage S, et al. Criterion-related validity of the last 7-day, short form of the International Physical Activity Questionnaire in Swedish adults. Public Health Nutr 2006;9:258-65.

6. Hagströmer M, Oja P, Sjöström M. The International Physical Activity Questionnaire (IPAQ): a study of concurrent and construct validity. Public Health Nutr 2006;9:755-62.

7. Kurtze N, Rangul V, Hustvedt BE, Flanders WD. Reliability and validity of self-reported physical activity in the NordTrøndelag Health Study (HUNT 2). Eur J Epidemiol 2007;22:379-387

8. Martínez-González MA, López-Fontana C, Varo JJ, Sánchez-Villegas A, Martinez JA. Validation of the Spanish version of the physical activity questionnaire used in the Nurses' Health Study and the Health Professionals' Follow-up Study. Public Health Nutr 2005;8:920-7.

9. Guidelines for Data Processing and Analysis of the International Physical Activity Questionnaire - Short and Long Forms. 2005 Available at: http://www.ipaq.ki.se. Access date: Jan 11, 2010.

10. American College of Sports Medicine. Physical fitness testing. In: ACSM's Guidelines for Exercise Testing and Prescription. London: Williams \& Wilkins. 1995:49-78.

11. Nunnally JC. In: Psychometric theory. New York: McGraw-Hill. 1994, Pp: 440-51.

12. Anastasia A. Validity: Basic Concepts. In: Psychological Testing. 6th edition. New York: Macmillan Publishing Company. 1990:139-157.

13. Kriska AM, Casprsen CJ. A collection of physical activity questionnaires for health-related research. Med SciSports Exerc 1997;29:S1-S205.

14. US. Department of Health and Human Services. Physical Activity and Health: A Report of the Surgeon General. Atlanta, GA: Centers for Disease Control and Prevention, National Center for Chronic Disease Prevention and Health Promotion. 1996.

15. Singh PN, Tonstad S, Abbey DE, Fraser GE. Validity of selected physical activity questions in white Seventhday Adventists and non-Adventists. Med Sci Sports Exerc 1996;28:1026-37.

16. Ainsworth BE, Leon AS, Richardson MT, Jacobs DR, Paffenbarger RSJ. Accuracy of the College Alumnus Physical Activity Questionnaire. J Clin Epidemiol 1993;46:1403-11.

17. Jacobs DRJ, Ainsworth BE, Hartman TJ, Leon AS. A simultaneous evaluation of 10 commonly used physical activity questionnaires. Med Sci Sports Exerc 1993;25:81-91

18. Kriska A. Ethnic and cultural issues in assessing physical activity. Res Q Exerc Sport 2000;71:47-53.

19. Richardson MT, Ainsworth BE, Jacobs DR, Leon AS. Validation of the Stanford 7-day recall to assess habitual physical activity. Ann Epidemiol 2001;11:145-53

20. Wareham NJ, Jakes RW, Rennie KL, et al. Validity and repeatability of the EPIC-Norfolk Physical Activity Questionnaire. Inter J Epidemiol 2002;31:168-174.

21. Richardson MT, Leon AS, Jacobs DR Jr., Ainsworth BE, Serfass R. Ability of the Caltrac accelerometer to assess daily physical activity levels. J Cardiopulm Rehabil 1995;15:107-13.

22. Brown W, Bauman A, Chey T, Trost S, Mummery K. Comparison of surveys used to measure physical activity. Aust NZ J Public Health 2004;28:128-34. 
23. Rzewnicki R, Vanden Auweele Y, De Bourdeudhuij I. Addressing overreporting on the International Physical Activity Questionnaire (IPAQ) telephone survey with a population sample. Pub Health Nutr 2003;6:299-305.

24. Centers for Disease Control and Prevention (CDC). Prevalence of no leisure-time physical activity - 35 states and district of Columbia, 1988-2002. MMWR Morb Mortal Wkly Rep 2004;53:82-6.

25. Forrest K, Bunker C, Kriska A, et al. Physical activity and cardiovascular risk factors in a developing population. Med Sci Sports Exerc. 2001;33:1598-604.

26. Martin S, Morrow I, Jackson A, Dunn A. Variables related to meeting the CDC/ACSM physical activity guidelines. Med Sci Sports Exer 2000;32:2087-92. 


\section{Appendix}

\section{International Questionnaire of Physical Activity}

This questionnaire is available at:

http://journals.tums.ac.ir/upload files/pdf/ /20012.pdf (In Persian Version)

https://sites.google.com/site/theipaq/questionnaires (In other language) 